\title{
A educação do cidadão da e na sociedade da informação e da comunicação
}

\section{The education of the citizen in the Information and Communication Society}

\section{La educación del ciudadano y de la sociedad de la información y de la comunicación}

\author{
Miguel Alfredo Orth ${ }^{1}$
}

DOI: http://dx.doi.org/10.20435/serie-estudos.v22i46.1075

\begin{abstract}
Resumo: O presente artigo busca problematizar a educação do cidadão da e na sociedade da informação e da comunicação. Metodologicamente, a pesquisa apoia-se em uma revisão bibliográfica das tecnologias da informação e da comunicação, ou seja, buscou-se clarear como os nativos digitais interagem e apreendem auxiliados pelas tecnologias da informação e da comunicação. Para isso considerou-se importante pesquisar também a temática no contexto educacional, em especial na educação do cidadão do século XXI. Ao longo deste estudo reforçou-se a convicção de que, em uma sociedade estruturada de forma global e em rede, precisamos estar abertos para novas estratégias de ensino e de aprendizagem que reforça a educação do cidadão para a sociedade da informação e da comunicação. Quer dizer, a educação do século XXI também precisa ser repensada com o auxílio das tecnologias da informação e da comunicação e de novas metodologias de ensino e de aprendizagem, em especial estratégias de ensino e de aprendizagem dialógicas, colaborativas, interativas, construtivas, autônomas e mediatizadas. E para que isso ocorra se faz necessário igualmente repensar os processos de formação de professores, a própria estrutura escolar e dos sistemas de ensino e as relações e ou interações educativas nelas cultivadas.
\end{abstract}

Palavras-chave: informática e educação; educação cidadã; informática educativa.

Abstract: The present article seeks to problematize education in the information and communication society. Methodologically, we have adopted bibliographical research and information and communication technologies, that is, we sought to clarify how digital natives interact and apprehend aided by information and communication technologies. For this we've consider important to research the theme in educational context, in special for the education of the citizen from the XXI century. Throughout this study we have been reinforcing the conviction that in a society structured in a global and networked way, we need to be open to new teaching and learning strategies that reinforce citizens' education for the information and communication society. That is to say, 21st century education needs to be rethought with the help of information and communication technologies and new teaching and learning methodologies, especially teaching and learning strategies, dialogic, collaborative, interactive, constructive, autonomous and Mediated. And for this to happen it is also necessary to rethink

${ }^{1}$ Universidade Federal de Pelotas (UFPel), Pelotas, Rio Grande do Sul, Brasil. 
the processes of teacher training, the school structure itself and the educational systems and the relationships and or educational interactions cultivated in them.

Key words: informatics and education; citizen education; educational informatics.

Resumen: El presente artículo busca cuestionar la educación de los ciudadanos de la sociedad de la información y de la comunicación. Desde el punto de vista metodológico, la investigación se basa en una revisión bibliográfica de las tecnologías de la información y la comunicación, es decir, hemos procurado aclarar cómo los nativos digitales interactuar y aprender ayudados por las tecnologías de la información y de la comunicación. Para esto también se consideró importante investigar la temática en el contexto educativo, especialmente en la educación de los ciudadanos del siglo XXI. A lo largo de este estudio se ha reforzado la convicción de que, en una sociedad estructurada de manera global y en red, tenemos que estar abiertos a nuevas estrategias de enseñanza y aprendizaje que fortalece la educación de los ciudadanos de la sociedad de la información y la comunicación. O mejor, la educación del siglo XXI también necesita ser repensada con la ayuda de las tecnologías de la información y la comunicación y de nuevas metodologías de enseñanza y aprendizaje, en particular de estrategias de enseñanza y aprendizaje dialógicas, colaborativas, interactivas, constructivas, autónomas y mediada. Y para que esto ocurra también se hace necesario repensar los procesos de formación de los maestros, bien como la propia estructura de la escuela y de los sistemas de enseñanza y de las relaciones e interacciones educativas cultivadas en las mismas.

Palabras clave: ciencias de la computación y educación; la educación ciudadana; la educación en tecnología de la información.

\section{INTRODUÇÃO}

Nos dias de hoje, em meio aos diferentes afazeres, é corriqueiro adultos se surpreenderem com a naturalidade com que jovens e até crianças interagem mediados pelas Tecnologias da Informação e da Comunicação. Em muitas circunstâncias, os adultos até estranham a naturalidade com que crianças e jovens interagem com as tecnologias e, por vezes, até implicam com os mesmos, muito em função de seus hábitos midiáticos, já que os adultos foram criados e educados supervalorizando modelos presenciais de interação. O mundo virtual encurta as distâncias, trazendo para dentro das casas as mais diferentes visitas, a qualquer hora do dia, reconfigurando assim os espaços, os tempos e as próprias relações familiares, bem como as relações das famílias com os outros e o mundo. Isso também pode ser observado quando jovens e adolescentes, individualmente ou em grupo, interagem de forma prazerosa e descontraída com o auxílio de seus celulares ou de outros objetos eletrônicos de seu uso, jogando ou discutindo, conectados ou não com o mundo virtual.

Mas há que se dizer também que, em diferentes períodos históricos, o povo e seus indivíduos construíram suas bases sociais, políticas, econômicas e culturais, bem como sofre a influência de diferentes conexões locais, regionais, nacionais e mundiais. Essas bases econômicas, sociais, políticas e culturais, por sua vez, sofrem 
a influência de diferentes processos globalizantes ${ }^{2}$. Porém, há muitas divergências quanto à forma de se conceituarem esses processos, a ponto de nem mesmo os teóricos da área chegarem a um acordo sobre eles. Para ilustrar isso tiramos do livro do Boaventura de Souza Santos, A globalização e as Ciências Sociais o extrato que segue.

[...] A extraordinária amplitude e profundidade destas interações transnacionais levaram a que alguns autores as vissem como ruptura em relação às anteriores formas de interaç̧ões transfronteiriças, um fenômeno novo designado pro "globalização" (Featherstone, 1990; Giddens, 1990; Albrow e King, 1990), "formação global" (Chase-Dunn, 1991), "cultura global" (Appadurai, 1990, 1997; Robestson, 1992), "sistema global" (Sklair, 1991), "modernidades globais" (Featherstone et al. 1995), "processo global" (Friedman, 1994), "cultura da globalização" (Jameson e Miyoshi, 1998) ou "cidades globais" (Sessen, 1991, 1994; Fornuna, 1997). (SANTOS, 2002, p. 25).

Frente a essas complexas dimensões, que envolvem a sociedade, a política, a economia, a cultura e suas variantes, nos dias de hoje, decidimos fazer o presente artigo, focando em uma ampla revisão bibliográfica sobre a sociedade da informação e da comunicação e os processos educacionais cidadãos que precisam ser privilegiados sempre que se quer educar o cidadão do século XXI.

Segundo Macedo (1994), o conceito restrito de revisão bibliográfica é definido pela busca de informações bibliográficas, seleção de documentos que se relacionam com o problema da pesquisa e o fichamento deles por meio de seus referenciais para usos posteriores.

Assim, na revisão bibliográfica, procurou-se identificar o conhecimento científico acumulado sobre a sociedade da informação e da comunicação e alguns princípios pedagógicos capazes de desafiar os nativos digitais em seu processo de aprendizagem. Para isso leu-se e efetuou-se o fichamento de diferentes artigos e livros científicos que trabalham a temática da sociedade da informação e da comunicação e alguns princípios pedagógicos capazes de potencializar as aprendizagens dos nativos digitais.

Ou seja, objetiva-se, com este artigo aprofundar o estudo em torno da sociedade da informação e da comunicação e da educação do cidadão ${ }^{3}$ desta sociedade.

\footnotetext{
${ }^{2}$ No entendimento de Giddens (1990, p. 64), o processo de globalização não é nada mais, nada menos do que "a intensificação de relações sociais mundiais que unem localidades distantes de tal modo que os acontecimentos locais são condicionados por eventos que acontecem a muitas milhas de distância e vice versa".

${ }^{3}$ Indivíduo que goza de direitos civis e políticos de um Estado, ou no desempenho de seus deveres para com este (FERREIRA, 2009), bem como aquele indivíduo que consegue transitar autonomamente
} 
Com isto busca-se também entender como os nativos digitais constroem o seu conhecimento, bem como estes interagem com a escola e a sociedade, para poder potencializar a construção do conhecimento deles.

Essas novas formas de se aprender na sociedade da informação e da comunicação são distintas das formas de aprender de nossos pais e avós em um passado não muito distante e que também precisam ser problematizadas na escola e na sociedade para se educar o cidadão do século XXI. Neste artigo temos a intenção de discutir a educação dos cidadãos da e na sociedade da informação e da comunicação, no intuito de contribuir com os processos de escolarizações dos sujeitos dessa sociedade.

\section{A SOCIEDADE DA INFORMAÇÃO E DA COMUNICAÇÃO}

Pierre Lévy (1996, p. 19), em seu livro As tecnologias da Inteligência, já defendia a tese de que: "[...] Os coletivos cosmopolitas compostos de indivíduos, instituições e técnicas não são somente meios ou ambientes para o pensamento, mas seus verdadeiros sujeitos". Para chegar a essa tese, o autor foi mostrando como o ser humano, ao longo da história, se valeu de diferentes estratégias, denominadas por ele de "diferentes tempos de espírito". Ele explorou as especificidades de cada tempo e mostrou que o tempo da oralidade primária foi dotado de estratégias distintas das adotadas ao longo do tempo da escrita e do tempo da informática e vice-versa.

Ao falar do último tempo, hoje em dia amplamente disseminado, Lévy (1996) preocupou-se com o tipo de tempo que o informacional oculta e encobre. Mais especificamente, ele se perguntava:

Qual seria o tempo secretado pela informatização? A maneira antiga de escrever os signos era conveniente para o cidadão ou camponês. O computador e as telecomunicações correspondem ao nomadismo das megalópoles e das redes internacionais. Ao contrário da escrita, a informática não reduplica a inscrição sobre o território; ela serve à mobilização permanente dos homens e das coisas que talvez tenha começado com a revolução industrial. A escrita era o eco, sobre um plano cognitivo, de invenção sociotécnica do tempo delimitado e do estoque. A informática, ao contrário, faz parte do trabalho de reabsorção de um espaço-tempo social viscoso, de forte inércia, em proveito de uma reorganização permanente e em tempo real dos agenciamentos sociotécnicos: flexibilidade, fluxo tensionado, estoque zero, prazo zero. (LÉVY, 1996, p. 114).

Como expressa muito bem Lévy (1996), a sociedade da informação e da comunicação tem um jeito próprio de lidar com a informação e de apropriar-se dela,

em uma sociedade por que domina os recursos que a constitui. 
criando assim subjetividades e representações sociais, culturais, econômicas e políticas próprias. Por outro lado, as modernas técnicas de armazenamento, tratamento e transmissão de informações criam também diferentes processos e níveis de empilhamento de endereços informacionais (LEMOS; LÉVY, 2010).

Assim, por exemplo, na década de 1950, os bits de informação eram direcionados para as memórias dos computadores. Num segundo momento, essa movimentação das informações ocorreu via Internet, quando elas passaram a ser endereçadas aos servidores de informação ligados em redes. Já no momento atual, vivemos o endereçamento da informação via web, ou seja, criam-se diferentes ambientes virtuais que endereçam diferentes páginas e documentos a um único site por meio de hiperligações.

Miranda (2000, p. 79) diria que essa

[...] convergência tecnológica vem eliminando os limites entre os meios, tornando-os solidários em termos operacionais, e erodindo as tradicionais relações que mantinham entre si e com seus usuários. Na verdade, com a tecnologia digital, torna-se possível o uso de uma linguagem comum: um filme, uma chamada telefônica, uma carta, um artigo de revista, qualquer deles pode ser transformado em dígitos e distribuído por fios telefônicos, microondas, satélites ou ainda por via de um meio físico de gravação, como uma fita magnética ou um disco. Além disso, com a digitalização, o conteúdo torna-se totalmente plástico, isto é, qualquer mensagem, som, ou imagem pode ser editada, mudando de qualquer coisa para qualquer coisa.

Essas novas tecnologias da informação e da comunicação (TIC) são idolatradas, alimentadas e reforçadas pelos próprios meios de comunicação social e por muitas crianças, jovens e até adultos que passam horas assistindo à televisão, jogando games, escutando música e ou mesmo conversando com seus pares ou amigos, todos nativos ou imigrantes digitais. E ao fazer isso, eles(as)

[...] processam quantidades enormes de informações por meio de uma grande variedade de tecnologias e meios. Elas[es] se comunicam com amigos e outras pessoas de maneira muito mais intensa do que as gerações anteriores, usando a televisão, o MSN, os telefones celulares, os iPods, os blogs, os Wikis, as salas de bate-papo na internet, os jogos e outras plataformas de comunicação. Usam esses recursos e essas plataformas em redes técnicas globais, tendo o mundo como quadro de referência. (VEEN; VRAKKING, 2009, p. 29).

E, para fazer tudo isso, as gerações denominadas digitais precisam ter acesso apenas a três pequenos aparelhos em particular: o controle-remoto da televisão, o mouse do computador e o telefone celular. O uso desses três aparelhinhos influencia, de maneira decisiva, o modo de ser, fazer e pensar dessa geração, também conhecida 
como geração de nativos digitais, que Veen e Vrakking (2009) denominam de Homo zappiens ${ }^{4}$.

Para os nativos digitais, as informações e as pessoas que eles buscam estão sempre a um clique. Eles organizam sua vida sabendo que não precisam saber tudo, mas precisam saber buscar cada informação no lugar certo, selecioná-la, depurá-la, reconstruí-la ou construí-la e divulgá-la ou, ainda, saber com quem entrar em contacto para ter acesso a essa informação, mercadoria ou bem.

[...] O Homo zappiens aprende muito cedo que há muitas fontes de informação e que essas fontes podem defender verdades diferentes. Filtra as informações e aprende a fazer seus conceitos em redes de amigos/parceiros com que se comunica com frequência. (VEEN; VRAKKING, 2009, p. 29).

Assim, o Homo zappiens, ou o nativo digital, além de zapear por diferentes canais e páginas da web, habituou-se a fazer várias coisas ao mesmo tempo, desde ouvir sua música favorita no MP3, CD ou mesmo em um celular, responder mensagens no Facebook ou no Whatsapp e, caso tenha uma TV no quarto, ainda assistir a um programa de TV ou vídeo.

De fato, o Homo zappiens consegue dividir sua atenção entre os diferentes sinais de entrada de informação, selecionar e direcionar sua atenção para processar cada informação no momento e no nível desejado, de acordo com seus interesses. E faz isso sem muita dificuldade e em proporções impressionantes. Segundo Lindström e Seybold (apud VEEN; VRAKKING, 2009), o Homo zappiens consegue absorver cerca de oito mil imagens de marcas ou de logomarcas por dia.

Tal carga de informação pode parecer excessiva para os pais ou para quem nasceu antes da década de 1980, mas o Homo zappiens não considera o fato de ter de processar grandes quantidades de informação um problema. Ele adotou o computador e a tecnologia da mesma forma que as antigas gerações fizeram com a eletricidade; a informação e a tecnologia da informação tornaram-se parte integrante de sua vida. (VEEN; VRAKKING, 2009, p. 34).

Ou seja, o sujeito da sociedade da informação e da comunicação lida com extrema facilidade com os computadores, sem mesmo fazer cursos específicos na área. Ele manipula seus telefones celulares, envia mensagens usando um ou mais dedos. Além disso, tem um amplo conhecimento sobre os procedimentos a seguir

\footnotetext{
${ }^{4}$ Neste artigo, utilizamos o termo Homo zappiens para nos referirmos à geração de seres humanos que cresceram usando múltiplos recursos tecnológicos desde a infância, e não no sentido etimológico do termo latino homo sapiens - homem sábio.
} 
para baixar ou modificar arquivos de música, utilitários de compactação de arquivos ou mesmo ferramentas de programação. Em geral, os nativos digitais não são especialistas em tecnologia, mas são especialistas em baixar para o seu computador os programas e as informações que buscam na rede e instalá-los para o seu uso. A maioria dos nativos digitais nem se interessa pela tecnologia em si, sendo apenas ávidos consumidores da mesma.

Os adolescentes e jovens dessa geração tratam a tecnologia como um produto amigável e útil e, sempre que um novo produto surge no mercado, consultam as pessoas de suas relações sobre seu funcionamento. Em especial, buscam saber como cada aparelho ou produto poderia ajudá-los no seu cotidiano, já que, para eles, o critério principal para adotar uma nova tecnologia não é o fato de o software ter ou não uma boa usabilidade, e sim a capacidade de atender ou não às suas exigências e necessidades momentâneas.

Mas todos esses processos também envolvem outra questão fundamental. Se, por um lado, para os nativos digitais é importante saber usar o recurso tecnológico e adquirir novas habilidades, por outro lado, a influência do uso das tecnologias vai muito além do desenvolvimento de habilidades operacionais para interagir com ela.

Como podemos observar, a sociedade da informação e da comunicação instiga-nos a navegar por diferentes mundos em um oceano de possibilidades. Por isso faz-se necessário problematizar a educação do cidadão na sociedade da informação e da comunicação.

\section{A EDUCAÇÃO NA E PARA A SOCIEDADE DA INFORMAÇÃO E DA COMUNICAÇÃO}

A sociedade da informação e da comunicação vem disseminando, pelo mundo afora, novos conceitos de vida, cultura, organização social, etc. e criando novas interações e representações sociais. Essas influências, as jovens gerações vêm recebendo desde muito cedo, uma vez que o mundo chega até elas por meio da televisão, do telefone, da Internet, etc., cabendo à escola educar e ou reeducar o cidadão desta nova sociedade.

A cidadania define a pertença a um Estado. Ela dá ao indivíduo um status jurídico, ao qual se ligam direitos e deveres particulares. Esse status depende das leis próprias de cada Estado, e pode-se afirmar que há tantos tipos de cidadãos quantos tipos de Estado. O problema da cidadania, porém, não é apenas problema jurídico ou constitucional; se provoca debates apaixonados, é porque 
coloca a questão do modo de inserção do indivíduo em sua comunidade, assim como a de sua relação com o poder político. (CANIVEZ, 1991, p. 15).

Essa definição genérica de cidadania, se trazida para a realidade brasileira e para o contexto deste estudo, passa pela concepção de cidadania do estado nacional e dos diferentes entes federativos, mas também pela concepção de cidadania de cada partido político, ideólogo, teórico, bem como pela concepção de cidadania de cada brasileiro. Mas o ponto de partida é a constituição e, para os educadores, também o é a Lei de Diretrizes e Bases da Educação Nacional (LDB).

Essas concepções de cidadania perpassam os espaços escolares e seus princípios norteadores, os quais se confrontam com as concepções dos pais, alunos, professores e da própria equipe diretiva. Diferentes teóricos também problematizam a cidadania e a relacionam, inclusive, com a sociedade da informação e da comunicação. Morin (2001), Perrenoud (2000), Sancho (2006), Gadotti (2000) e Moran, (2007), entre tantos outros, por exemplo, entendem que a escola tem um papel fundamental na organização de movimentos globais e de renovação cultural e entendem que ela deve aproveitar toda essa riqueza que a sociedade informacional, global e em redes (CASTELLS, 2006) desvela para repensar seus próprios processos educativos para educar o cidadão do século XXI. E mais:

Na sociedade da informação, a escola deve servir de bússola para navegar nesse mar do conhecimento, superando a visão utilitarista de só oferecer informações "úteis" para a competitividade, para obter resultados. Deve oferecer uma formação geral na direção de uma educação integral. O que significa servir de bússola? Significa orientar criticamente, sobretudo as crianças e jovens, na busca de uma informação que os faça crescer e não embrutecer. (GADOTTI, 2000, p. 6).

Mas como a escola pode educar esse cidadão se ela nem sempre consegue cumprir com seu dever sagrado de ensinar o "B, A, BA" sem sofrer a influência do contexto social, político, econômico e cultural do seu entorno? Ou, ainda, por que a escola, mesmo sofrendo a influência das diferentes correlações sociais, políticas, econômicas e culturais, se transforma em um ente pesado e prudente? Moran (2007) entende que a escola e as universidades são:

Prudente, para não embarcar em qualquer aventura, porque precisa preservar o passado, olhar para o presente e preparar o futuro. Prudente, porque tem de encontrar denominadores comuns mínimos compatíveis com as diferenças e desigualdades nacionais e regionais. É pesada, porque burocratizou tanto toda a gestão em todos os níveis que, mesmo aumentando as ações de capacitação, parece que quase nada muda. Há uma sensação de desperdício de recursos, 
de não sair do lugar, de experiências pontuais interessantes, mas de extrema lerdeza, de peso cultural imobilizador. (MORAN, 2007, p. 15).

Além disso, muitas escolas e universidades que historicamente eram identificadas com suas cidades, seus estados e regiões, hoje são influenciadas por diferentes processos informacionais, globais e em rede. Essas mudanças sociais e tecnológicas do mundo hodierno fazem com que muitas escolas e universidades, ao se expandirem embebidas de políticas e intenções globalizantes, não raro, percam sua identidade local, regional e/ou nacional.

Esses movimentos e reconfigurações, segundo Gadotti (2000), trazem a certeza de que, na educação,

[...] necessita-se de maior integração entre os espaços sociais (domiciliar, escolar, empresarial, etc.), visando equipar o aluno para viver melhor na sociedade do conhecimento. Como previa Herbert McLuhan, o planeta tornou-se a nossa sala de aula e o nosso endereço. O ciberespaço não está em lugar nenhum, pois está em todo o lugar o tempo todo. Estar num lugar significaria estar determinado pelo tempo (hoje, ontem, amanhã). No ciberespaço, a informação está sempre e permanentemente presente e em renovação constante. O ciberespaço rompeu com a idéia de tempo próprio para a aprendizagem. Não há tempo e espaço próprios para aprendizagem. (GADOTTI, 2000, p. 6).

Assim, se faz necessário repensar as concepções de ensino e de aprendizagem para as escolas e universidades do século XXI, de sorte que estas deem conta das exigências da sociedade da informação e da comunicação e assim possamos educar o cidadão do século XXI em novas bases. Tais concepções aproximam o conhecimento, a cultura e a comunicação, bem como ajudam a buscá-los e pensá-los a partir de novos parâmetros teóricos e conceituais.

Agora, para educarmos com qualidade para e na sociedade da informação e da comunicação, também se faz necessário organizar e gerenciar o fazer didático-pedagógico escolar. Para isso, precisamos reorganizar os ambientes presenciais; oferecer atividades em ambientes presenciais conectados; utilizar ambientes virtuais de aprendizagem; inserir ambientes experimentais, profissionais e culturais no fazer didático-pedagógico escolar; e pensar novos espaços e novos tempos para a aprendizagem (MORAN, 2007).

Sancho (2006), ao problematizar as concepções de ensino e de aprendizagem vigentes e profundamente arraigadas nas escolas e na sociedade da informação e da comunicação, aponta sete axiomas necessários para converterem-se as TIC no motor de toda e qualquer inovação pedagógica. Segundo ela, a escola do conhecimento, 
para produzir essa conversão, precisa enfrentar axiomas como: adquirir e implantar uma infraestrutura tecnológica adequada; utilizar os meios tecnológicos nos processos de ensino e aprendizagem; dar um enfoque construtivista à gestão escolar; investir na capacidade de o aluno adquirir sua própria educação; estar aberta à impossibilidade de se preverem os resultados da aprendizagem; ampliar o conceito de interação docente; questionar o senso pedagógico comum. Claro sem menosprezar as categorias ou axiomas que outros autores discutem.

Consideramos esses axiomas de extrema importância para se repensar a escola em uma sociedade da informação e da comunicação, mas gostaríamos de chamar atenção para alguns deles, visto que exercem uma função fundamental no processo de reinvenção da escola e de seus processos de ensino e de aprendizagem e que, por vezes, são descuidados. Um desses axiomas traz para a discussão o enfoque construtivista da gestão. Esse axioma reside no fato de que planejar e gerir a escola na era da informação exigem que se considere o

[...] contexto social do ensino para poder tomar decisões sobre a própria estrutura da escola, a concepção do currículo, a própria forma de tomar decisões, o papel dos diferentes membros da comunidade escolar, os sistemas de comunicação externa e interna, as características dos recursos necessários e como consegui-los e o desenvolvimento pessoal e profissional dos professores. (SANCHO, 2006, p. 30).

Isso exigirá uma ampla reestruturação das escolas, bem como uma mudança na forma de geri-las e pensá-las. Porque, para desencadear esse processo na escola e nos sistemas de ensino, se faz necessário dominar a teoria que o fundamenta, bem como as consequências práticas da aplicação dessa teoria na escola, com o respaldo do sistema de ensino.

Outro axioma de Sancho que gostaríamos de destacar aqui diz respeito à utilização de novos meios para se desencadearem os processos de ensino e de aprendizagem. Sim, porque, se queremos que as TIC se transformem em meios privilegiados de ensino e de aprendizagem inovadores, precisamos ousar revisar os currículos escolares, fazendo nossas as perguntas de Sancho.

Até que ponto e em que sentido o currículo vigente favorece a utilização das TIC? Que aspectos de conteúdo e prática do ensino teriam que mudar para poder garantir uma utilização generalizada e gradativamente valiosa das TIC na escola? Até que ponto e em que sentido as propostas de uso das TIC derivadas da administração educativa fomentam sua aplicação nos diferentes aspectos do currículo? Que tipo de formação necessitam os professores para garantir uma utilização das TIC orientada para a melhoria do ensino? (SANCHO, 2006, p. 28). 
Essa reestruturação curricular, bem como da própria forma de se gerir e pensar a escola, é necessária para educar o cidadão do século XXI, uma vez que tem reflexo na concepção de construção de conhecimento de cada aluno, professor e escola. Essa concepção, muitas vezes, vai até na contramão da mera transmissão. Para que se efetive esse axioma, a escola precisa apropriar-se e fazer uso de outros axiomas, como o da interação. Em especial, deve-se considerar como a escola, a equipe diretiva, os professores, os alunos e a própria comunidade concebem a interação no processo de ensino e de aprendizagem.

Para Freire (1987), a interação passa necessariamente pelo estabelecimento de diálogos, e não monólogos. Segundo ele, para haver diálogo, é preciso que cada sujeito pronuncie a palavra e ouse ouvir o outro pronunciar a sua palavra. "O diálogo é este encontro dos homens mediatizados pelo mundo, para pronunciá-lo, não se esgotando, portanto, na relação eu-tu" (FREIRE, 1987, p. 78). Freire não reforça o diálogo dos surdos que a sociedade consumista e excêntrica engendra, e sim um processo de ouvir o outro e de ousar pronunciar a palavra.

Porém, ao desencadear-se esse processo, o professor e a escola precisam ter consciência de que, em seus atos educativos, precisam igualmente desequilibrar o aprendiz (PIAGET, 1976). Mas a arte de ser mestre, de ser professor, não consiste no mero processo de desequilibrar o aprendiz. Isso qualquer cidadão pode fazer. A arte de ser professor é a arte de usar uma mão para desequilibrar o aprendiz e a outra para conduzir o aprendiz a um novo equilíbrio, por meio do processo de assimilação e de acomodação do conhecimento construído e ou reconstruído.

Quanto ao fato de adquirir e implantar uma infraestrutura tecnológica adequada, nós nos perguntamos: como fazer isso se, muitas vezes, as escolas nem têm infraestrutura física para desencadear os processos de ensino e de aprendizagem que Ihes são inerentes? E como garantir que a infraestrutura adquirida e implantada seja apropriada pelos professores para qualificar seu fazer didático-pedagógico? Como assegurar que os alunos façam uso desses recursos para dinamizar seus processos de aprendizagem? Como garantir a manutenção da infraestrutura tecnológica implantada?

Também precisamos questionar o senso pedagógico comum, ou, como diria Sancho (2006, p. 33): "é imprescindível uma profunda revisão e o questionamento das conviç̧ões pedagógicas relativas ao que é e não é 'uma idade apropriada' para aprender, quem pode realizar escolhas pedagógicas válidas e como deve funcionar o controle do processo educacional". Este último aspecto também nos leva a repensar 
o axioma de Sancho sobre a impossibilidade de se preverem os resultados da aprendizagem. Aliás, é interessante observar que Sancho (2006) propõe justamente esse axioma no momento em que o Banco Mundial e todas as agências internacionais de fomento educacional condicionam suas ajudas na área a processos de avaliação contingenciados pela previsão de aprendizagens realizadas pelos educandos.

Além desses autores que discutem as implicações pedagógicas das TIC, também encontramos autores de renome internacional, como Morin (2001) e Perrenoud (2000), que, mesmo não tendo uma interface direta com as TIC, discutem a educação para e na sociedade da informação e da comunicação. Ao fazerem isso, abordam os saberes necessários para se educar o cidadão do século XXI.

O Relatório da Comissão Internacional sobre Educação para o século XXI da UNESCO, publicado no Brasil sob o título Educação um tesouro a descobrir, por sua vez, resume sua preocupação com a educação na sociedade da informação e da comunicação nos quatro pilares da educação, quais sejam: a) aprender a conhecer; b) aprender a fazer; c) aprender a viver juntos; e d) aprender a ser. Além disso, Delors (1999) destaca a importância fundamental de se trabalhar, nessa nova sociedade, a formação continuada em todos os níveis e modalidades.

A esses quatro pilares da educação, Gadotti (2000) acrescenta mais oito categorias educacionais que, segundo ele, precisam ser privilegiadas na educação do século XXI para se educar o cidadão do mundo. São categorias ou temas como: cidadania, planetariedade, sustentabilidade, virtualidade, globalização, dialogicidade, transdisciplinaridade e dialeticidade.

Esses seriam alguns teóricos, entre tantos outros, que abordam as implicações das TIC na educação e na sociedade da informação e da comunicação. Se isso é verdade, cabe a todos os envolvidos com a educação pesquisar, repensar e reavaliar os processos de ensino e de aprendizagem privilegiados nas escolas e nos sistemas educacionais para educar o cidadão do século XXI e ou da sociedade da informação e da comunicação.

\section{CONSIDERAÇÕES FINAIS}

Um novo tempo, um novo espaço e outras maneiras de pensar e fazer educação são exigidos na sociedade da informação. O amplo acesso e o amplo uso das novas tecnologias condicionam a reorganização dos currículos, dos modos de gestão e das metodologias utilizadas na prática educacional. (KENSKI, 2003, p. 92). 
Sim, nos dias de hoje, as alterações no campo das ciências ocorrem a uma velocidade sem precedentes, criando sempre novas possibilidades de acesso às informações e de reorganização e reestruturação permanentes de todas as áreas do conhecimento, a partir do acesso e do uso das tecnologias da informação e da comunicação.

Somos da opinião de que as TIC vêm orquestrando um conjunto de ações que se constituem de um sem-número de paradoxos e contradições, inclusive na educação; estes, enquanto tais, retratam o próprio caráter difuso e desarticulado dessa nova realidade. O Brasil vive esse paradoxo e ou essas contradições, em especial, quando precisa repensar a educação escolar do cidadão para e na sociedade da informação e da comunicação.

Essas contradições nem sempre são compartilhadas pelas crianças, adolescentes e jovens, uma vez que estes têm uma maneira própria de ver, perceber, compreender, sentir e aprender com as TIC.

Os jovens "estão em outra", afirmam os autores, e isto significa outras necessidades, outras percepções, outros relacionamentos, além daqueles conhecimentos muitas vezes vazios de significado que lhes chegam por meio das escolas e dos livros, organizados racional e linearmente. São outras maneiras de compreender, de perceber, de sentir e de aprender, em que a afetividade, as relações, a imaginação e os valores não podem deixar de ser considerados. São alternativas de aprendizagem que os auxiliam a interagir, a escolher e a participar nas estruturas sociais e educativas. (PORTO, 2006, p. 45).

Veen e Vrakking (2009, p. 29) diriam que, "[...] ao assistir à televisão, [as crianças e os jovens] aprenderam a interpretar as imagens antes mesmo de aprender a ler, e a interagir ainda que de maneira bastante restrita, com um meio de comunicação de massa". Isso não pode ser negado, como também não podemos negar a sinergia que existe entre os nativos digitais e os recursos tecnológicos. Mas qual deve ser então, a postura dos educadores frente às tecnologias, à sociedade da informação e da comunicação e aos nativos digitais?

Gadotti (2000) entende que, nos dias de hoje, para se aprender, vale à pena recorrer a diferentes recursos:

Hoje vale tudo para aprender. Isso vai além da "reciclagem" e da atualização de conhecimentos e muito mais além da "assimilação" de conhecimentos. A sociedade do conhecimento possui múltiplas oportunidades de aprendizagem [...]; avaliações permanentes; debate público; autonomia da escola; generalização da inovação. As conseqüências para a escola e para a educação em geral 
são enormes; ter raciocínio lógico; fazer sínteses e elaborações teóricas; saber organizar o seu próprio trabalho; ter disciplina para o trabalho; ser independente e autônomo; saber articular o conhecimento com a prática; ser aprendiz autônomo e a distância. (GADOTTI, 2000, p. 6).

Se a educação do século XXI, por um lado, precisa buscar a atualização do professor, por outro, exige um repensar constante do papel e da função da escola. Essa questão é pouco discutida e problematizada, mas é vital para engendrar a educação do século XXI. Sim, porque não adiantará, ou adiantará muito pouco, repensar a formação do professor ou fazer críticas azedas ao professor e ao aluno se a sociedade e os sistemas de ensino não souberem repensar a escola. Gastam-se hoje muito tempo, esforço e dinheiro para formar o professor e equipar a escola, mas gastam-se pouco tempo, esforço e dinheiro para repensar o modelo de escola que queremos. Ou será que, a sociedade da informação e comunicação quer um tipo de escola e nossa pratica escolar continua reforçando a escola tradicional?

Gadotti (2000), Veen e Vrakking (2009) e Christensen, Horn e Hohnson (2009), entre tantos outros teóricos, dizem que não. E mais, Veen e Vrakking (2009) afirmam que os jovens gostam da tecnologia porque ela Ihes possibilita ficar no comando.

[...] Todos os recursos mencionados têm algo crucial em comum: eles dão ao usuário o controle de uma ampla variedade de fluxos de informação e comunicação. Qualquer usuário pode, a qualquer momento, ativar, mudar ou interromper esses recursos apertando um simples botão. Eles colocam o usuário em uma posição de controle para decidir qual informação processar ou com qual comunicação se envolver ou não. Eles não só capacitam o usuário a controlar o fluxo de informação, mas também o ajudam a lidar com a sobrecarga de informação e selecionar a informação de modo eficiente, adequadamente, prontamente e de acordo com suas necessidades. (VEEN; VRAKKING, 2009, p. 36).

Como é possível observar, o mundo tecnológico que envolve os cidadãos do século XXI faz com que os nativos digitais não só acessem e manuseiem os novos recursos tecnológicos, como também criem novas habilidades e novas oportunidades. Além disso, cria também as condições para que tomem as rédeas de seu fazer, pensar e ser, ficando assim no controle de todos os recursos que usam, e possibilita que descubram seu caminho e suas soluções em cada caso. Com isso, os usuários sentem-se instigados pelas próprias situações e pelos próprios programas a desafiar seus limites, sem, no entanto, perder o controle.

Nada disso, em momento nenhum, exclui a escola da formação do cidadão digital. A escola, sem dúvida, continua a constituir-se em um lugar privilegiado para 
formarmos essa geração digital, mesmo que isso a obrigue a reinventar-se, com base em princípios antropológicos, filosóficos, epistemológicos, éticos, políticos e cidadãos. Sim, porque

A escola é um dos espaços privilegiados de elaboração de projetos de conhecimento, de intervenção social e de vida. É um espaço privilegiado para experimentar as situações desafiadoras do presente e do futuro, reais e imaginárias, aplicáveis ou limítrofes. No entanto, a promoção do desenvolvimento integral da criança e do jovem só é possível com a união do conteúdo escolar e da vivência em outros espaços de aprendizagem. (MORAN, 2007, p. 167).

Entendemos, da mesma forma que Moran, que pensar em uma educação inovadora é antes de tudo pensar em uma educação cujo conhecimento seja integrador e inovador. Essa educação também precisa resgatar e desenvolver a autoestima e o autoconhecimento do aprendiz e do educador, ser capaz de focar na aprendizagem empreendedora e cidadã e, ainda, saber organizar a aprendizagem de forma flexível (MORAN, 2007).

Enfim, temos consciência de que, por si só, o ato de educar nesse novo contexto [...] é um processo complexo, que exige mudanças significativas, investimento na formação de professores, para o domínio dos processos de comunicação da relação pedagógica e o domínio das tecnologias. [...] [Enfim] não nos enganemos. Mudar não é tão simples e não depende de um único fator. (MORAN, 2007, p. 168).

Assim, se queremos que o uso das TIC ajude a transformar a educação, como foi discutido ao longo deste artigo, dando novas vozes e sentidos às aprendizagens das crianças, dos adolescentes e dos jovens do século XXI, muitas questões precisam ser trabalhadas. Há aspectos que precisam ser gerenciados pelas políticas públicas dos diferentes sistemas de ensino; outros precisam ser geridos pelas escolas; outros, pelos professores; outros, ainda, pelos alunos; outros, pelos pais e, por que não dizer também, pela sociedade organizada. O mais importante é que cada qual faça a sua parte para que os diferentes processos gestem e produzam a escola que a sociedade do conhecimento exige para formar o cidadão do século XXI.

\section{REFERÊNCIAS}

CANIVEZ, Patrice. Educar o cidadão? Campinas, SP: Papirus, 1991.

CASTELLS, Manuel. A era da informação: economia, sociedade e cultura. 9. ed. São Paulo: Paz e Terra, 2006. 
CHRISTENSEN, Clayton M.; HORN, Michael B.; JOHNSON, Curtis W. Inovação na sala de aula: como a inovação de ruptura muda a forma de aprender. Porto Alegre: ArtMed, 2009.

DELORS, Jacques (Org.). A educação para o século XXI: questões e perspectivas. 2. ed. Porto Alegre: Artmed, 1999.

FERREIRA, Aurélio Buarque de Holanda. Novo Dicionário Aurélio da Língua Portuquesa. Coordenação Mariana Baird Ferreira e Margarida dos Anjos. 4. ed. Curitiba: Edi. Positiva, 2009.

FREIRE, Paulo. Pedagogia do oprimido. 17. ed. São Paulo: Paz e Terra, 1987.

GADOTTI, Moacir. Perspectivas atuais da Educação. Revista São Paulo em Perspectiva, São Paulo, v. 14, n. 2, abr./jun. 2000. Disponível em: <http://www.scielo.br/pdf/spp/v14n2/9782. pdf>. Acesso em: 12 fev. 2017.

GIDDENS, Anthony. Sociology. Oxford: Polity Press, 1990.

KENSKI, Vani Moreira. Tecnologias e ensino presencial e a distância. Campinas, SP: Papirus, 2003. (Série prática pedagógica)

LEMOS, André; LÉVY, Pierre. O futuro da internet: em direção a uma ciberdemocracia planetária. São Paulo: Paulus, 2010.

LÉVY, Pierre. As tecnologias da inteligência: o futuro do pensamento na era da informática. Rio de Janeiro: Editora 34, 1996.

MIRANDA, Antônio. Sociedade da informação: globalização, identidade cultural e conteúdos. Ciência da Informação [online], Brasília, v. 29, n. 2, p. 78-88, maio/ago. 2000. Disponível em: <http://www.scielo.br/pdf/ci/v29n2/a10v29n2.pdf>. Acesso em: 14 nov. 2017, às 23h.

MORAN, José Manuel. Educação que desejamos: novos desafios e como chegar lá. Campinas, SP: Papirus, 2007.

MORIN, Edgar. Os sete saberes necessários à educação do futuro. 3. ed. São Paulo: Cortez; Brasília, DF: UNESCO, 2001.

PERRENOUD, Philippe. 10 novas competências para ensinar: convite à viagem. Porto Alegre: Artmed, 2000.

PIAGET, Jean. A equilibração das estruturas cognitivas. Rio de Janeiro: Zahar, 1976.

PORTO, Tânia Maria Esperon. As tecnologias de comunicação e informação na escola; relações possíveis... relações construídas. Revista Brasileira de Educação, Rio de Janeiro, v. 11, n. 31, p. 43-57, jan./abr. 2006. Disponível em: <http://www.scielo.br/pdf/rbedu/v11n31/ a05v11n31.pdf>. Acesso em: 29 jan. 2017, às 23h.

SANCHO, Juana Maria et al. Tecnologias para transformar a educação. Porto Alegre: Artmed, 2006.

SANTOS, Boaventura de Sousa. Os processos da globalização. In: (Org.). A globalização e as ciências sociais. 2. ed. São Paulo: Cortez, 2002. 
VEEN, Wim; VRAKKING, Ben. Homo zappiens: educando na era digital. Porto Alegre: Artmed, 2009.

\section{Sobre o autor:}

Miguel Alfredo Orth: Licenciatura plena em Estudos Sociais - Habilitação em História pelo Centro Universitário La Salle, mestrado e doutorado em Educação pela Universidade Federal do Rio Grande do Sul. Coordena o Grupo de Pesquisa Formação e Prática de Professores e as Tecnologias da Informação e da Comunicação (FORPRATIC) e participa do grupo de pesquisa Formação de Professores para o MERCOSUL/CONE SUL. É professor adjunto do Departamento de Fundamentos da Faculdade de Educação (FaE) da Universidade Federal de Pelotas (UFPel) e do Programa de Pós-Graduação em Educação (PPGE). E-mail: miorth2@yahoo.com.br

\section{Recebido em junho de 2017}

Aprovado para publicação em agosto de 2017 
